\title{
Study on the tribological properties of titanium alloy modified by surface
}

\section{texture composite DLC film}

\author{
Zheng Lili, Zhang Yonghai, Chen Wengang* \\ ( College of Mechanical and Transport, Southwest Forestry University, Kunming 650224, China ) \\ *E-mail: chenwengang999@163.com
}

Key words: Titanium alloy, Surface texture, DLC film, Friction

Abstract: The different width stripes were prepared on the Ti-6Al-4V alloy surface by using laser micro processing technology. Then, the DLC film was deposited on the textured surface by using radio frequency plasma enhanced chemical vapor deposition device. The tribological properties of the composite modified surface were detected by using UMT-2 Micro Friction and wear testing machine. The characteristics of the film were analyzed by X-ray photoelectron spectroscopy and Raman spectroscopy. The surface morphology of samples was observed by optical microscope and scanning electron microscope. The results show that the composite modified surface has a certain anti-friction and anti-wear effect in the condition of dry friction and oil bath lubrication.

\section{Introduction}

Titanium alloy is a kind of important structural metal as it has excellent mechanical properties, thermal properties and has excellent corrosion resistance. Ti-6Al-4V alloy is the most widely used Titanium alloy currently. Although titanium alloy has good properties, its hardness is low, and the wear resistance is very poor. There are many methods to improve the wear resistance of titanium alloy, and it can be classified into two categories. The first one is the surface modification of titanium alloy, which carried out by using various surface treatment methods to improve the anti-friction and wear resistance. The second is carried out by improving the lubrication properties of the material surface to achieve the effect of wear reducing. The first methods include surface texture (physical modification) and surface coating, infiltration of other elements (chemical modification) methods ${ }^{[1-3]}$. At present, many researchers had carried out some research work on the two surface modification methods. In the aspect of surface texturing, many researchers had prepared point hole or groove on the material surface. The results indicated that the point pit and the groove formed on the surface can store the oil in the process of friction pair moved to each other, provide the lubricating oil ${ }^{[4]}$, collect the wear debris ${ }^{[5]}$, prevent the surface damage. So the material surface friction and wear performance can be improved obviously. On the aspect of chemical surface modification, the DLC film deposited on the surface of the material were favored by majority researchers because of the excellent properties. Lin $^{[6]}$ had prepared metal doped diamond (Me-DLC) thin film on the titanium alloy surface by using Anodic laminar flow type rectangular gas ion source combined with unbalanced magnetron sputtering method. The results showed that the surface hardness and the bearing capacity of the $\mathrm{Ti}$ alloy substrate were improved, and the friction coefficient was decreased and the wear resistance was improved. Huang ${ }^{[7]}$ had prepared a kind of diamond like multilayer by using magnetic filtered cathodic vacuum arc deposition technique on the surface of Ti-6Al-4V alloy. The results showed that the friction coefficient and the wear resistance of the Ti-6Al-4V alloy was increased and the friction coefficient was decreased in the simulated body fluid. Liu ${ }^{[8]}$ alloy has prepared DLC film on the surface of Ti-6Al-4V alloy by 
using ion beam deposition technique. The results showed that the film had low friction coefficient and wear resistance property. These related studies have been carried out to improve the tribological properties of titanium alloy, but there are few reports on the surface composite modification of titanium alloy by combining two kinds of surface modification. In view of this, this study intends to make a composite modification on the surface of Ti-6Al-4V film and detect the anti-friction and anti-wear properties of the surface.

\section{Experimental materials and experimental process}

The experimental material is Ti-6Al-4V plate with $1.0 \mathrm{~mm}$ thickness. The material composition is shown in Table 1 . The sample was cut into $10 \mathrm{~mm} \times 10 \mathrm{~mm}$ slice by wire cutting machine.

Tab. 1 Ti-6Al-4V element content

\begin{tabular}{ccccccccc}
\hline Element & $\mathrm{Al}$ & $\mathrm{V}$ & $\mathrm{Fe}$ & $\mathrm{O}$ & $\mathrm{N}$ & $\mathrm{H}$ & $\mathrm{C}$ & $\mathrm{Ti}$ \\
\hline Content & 6.1 & 4.1 & 0.15 & 0.09 & 0.02 & 0.001 & 0.01 & other \\
\hline
\end{tabular}

Laser etching was processed by using the HGL-LSY50F laser processing equipment. The experimental operating voltage of $\mathrm{AC} 220 \mathrm{~V}$, the total output power is $75 \mathrm{~W}$ and the output current is 12.5A. A series of stripe texture surfaces were prepared by changing the diameter of the laser beam, which can be seen from Fig. 1. The width include 50um, 100um, 150um, 200um, the depth was 10 20um and accuracy was $\pm 5 \mathrm{um}$.

\section{Fig. 1 Sample surface texture diagram}

The deposition of DLC film was carried out by using the ordinary single room parallel plate electrode coupled with the radio frequency glow discharge PECVD system. The experimental process: (1) The pretreatment of the substrate samples- plasma cleaning, which broke away the impurities material adsorbed on the surface and improved the material interface state by ion bombardment and sputtering. After the plasma cleaning, it is helpful for the film base binding. Plasma cleaning is generally used to select the highest rate of $\mathrm{Ar}$ ion. In this study, the Ar ion cleaning parameters are shown in table 2. (2) Deposition parameters: DLC carbon source was chose methane $\mathrm{CH}_{4}$ gas and Ar gas as dilute gas. The specific technological parameters of DLC thin film deposited by RF-PECVD method were shown in Table 3, which followed the main parameters control principle of the DLC preparation by chemical vapor deposition method.

\begin{tabular}{cccccc}
\hline \multicolumn{5}{c}{ Tab. 2 Parameter of $\mathrm{Ar}^{+}$sputtering clean } \\
Argon flow $(\mathrm{sccm})$ & $\begin{array}{c}\text { Vacuum degree } \\
(\mathrm{Pa})\end{array}$ & $\begin{array}{c}\text { Radio frequency energy } \\
(\mathrm{W})\end{array}$ & Time ( min $)$ \\
\hline \multicolumn{7}{c}{2.5} & 50 & 15 \\
\hline 10 & Tab. 3 Preparation technical of DLC deposited by RF-PECVD \\
\hline Background & Working & Ar flow & CH4 flow & Incident & Deposition \\
vacuum $(\mathrm{Pa})$ & vacuum $(\mathrm{Pa})$ & $(\mathrm{sccm})$ & $(\mathrm{sccm})$ & power ( W $)$ & time ( min ) \\
\hline 2.5 & 25.5 & 15 & 15 & 100 & 30 \\
\hline
\end{tabular}

The surface texture of textured samples was observed using a vertical universal friction and wear testing machine with optical microscope (magnification 60 times) and XL30 Phillips scanning electron microscope. The element composition and chemical composition of DLC film were analyzed by X-ray photoelectron spectroscopy (XPS) and Raman spectra.

Friction and wear tests were carried out at atmosphere by using the UMT-2 friction and wear testing machine of CETR company. Si3N4 ceramic ball (diameter of $4 \mathrm{~mm}$, relative hardness of HV1400 1700) was chose as friction pair. The sliding mode was reciprocating linear movement 
with sliding speed of $5 \mathrm{~mm} / \mathrm{s}$ at $5 \mathrm{~mm}$ one-way distance. The load used in test was $2 \mathrm{~N}, 3 \mathrm{~N}, 4 \mathrm{~N}, 5 \mathrm{~N}$, $1 \mathrm{~N}$ and $6 \mathrm{~N}$ and the test time was 600s, respectively. The lubrication method is divided into dry friction and oil rich lubrication. Wear samples were observed by XL30 Phillips scanning electron microscope.

\section{Experimental results and discussion}

\section{Surface texture morphology}

Figure 2 is the surface texture morphology of a titanium alloy, which is obtained under the optical microscope attached to a vertical universal friction and wear testing machine. The 50um dimension texture is relatively vague due to the low magnification. The texture of $150 \mathrm{um}$ is clear and the 200um texture can be very intuitive to reflect the surface morphology of titanium alloy. that is, a very regular stripe texture formed on the titanium alloy surface after the laser equipment processing.
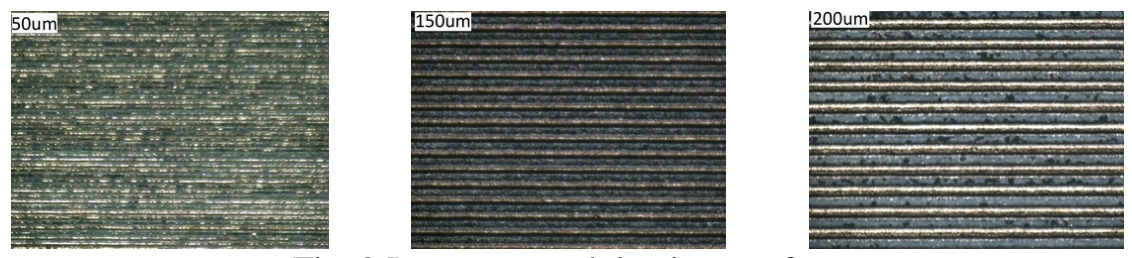

Fig. 2 Laser textured titanium surface

\section{DLC film characterization}

The composition and chemical structure of the deposited films on the surface of titanium alloy were analyzed by $\mathrm{X}$ ray photoelectron spectroscopy and Raman spectroscopy. Figure 3 is a X-ray photoelectron spectrum of the deposited film. The scanning range was $0 \sim 1000 \mathrm{eV}$ and the step size was $1 \mathrm{eV}$. It can be seen from the figure that the photoelectron excited by elements of the film were concentrated in 280 290eV, which is C. Table 4 show the peak height of each elements, half width, the area under peak and the relative content of each element. It is known that the $\mathrm{C}$ element content of the titanium alloy film is $98.22 \%$, and a small amount of oxygen is contained in the film. Figure 4 shows the Gaussian peak of $C_{1 s}$ with the software XPS peak 4.1. It can be seen from the graph that the peak of $\mathrm{C}_{1 \mathrm{~s}}$ can be divided into two peaks. The first is $\mathrm{sp}^{2}$ hybrid carbon corresponding to electron binding energy $284.3 \mathrm{eV}$, and the second is $\mathrm{sp}^{3}$ hybrid carbon corresponding to electron binding energy $284.8 \mathrm{eV}$.

Fig. 5 is the Raman spectra of DLC films prepared on the surface of titanium alloy. The spectral range is $1200 \sim 1800 \mathrm{~cm}^{-1}$. A Symmetric broad peak appeared in the scanning range. Two fitting peaks correspond to D peak and G peak can be obtained by Gauss fitting. The half width of D peak is $233 \mathrm{~cm}^{-1}$ and the half width of $\mathrm{G}$ peak is $123 \mathrm{~cm}^{-1}$. G peaks correspond to the structure of the $\mathrm{SP}^{2}$ cluster in the films, which derived from the stretching vibration $\mathrm{E}_{2 \mathrm{~g}}$ mode of the $\mathrm{C}-\mathrm{C}$ bond in the graphite structure. The $\mathrm{D}$ peak corresponds to the numerous small diamond structure derived from $\mathrm{A}_{1 \mathrm{~g}}$ mode of the Raman scattering.

The analysis showed that the $\mathrm{C}$ element film contained graphite structure and diamond structure. The area of D peak and G peak was calculated, and the area ratio of I (D) /I (G) was 1.056 (Table 5). It indicated that ratio of the diamond structure was close to $50 \%$, which is a typical diamond like carbon film (DLC film).

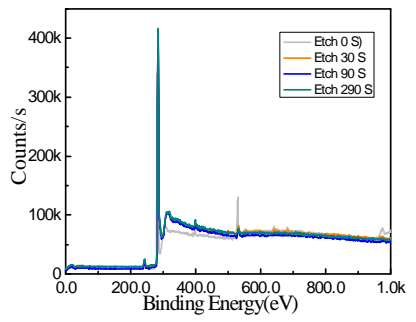

Fig. 3 XPS wide spectrum scanning

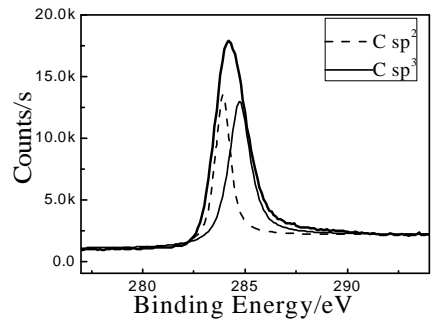

Fig. $4 \mathrm{C}_{1 \mathrm{~s}}$ peak of the film

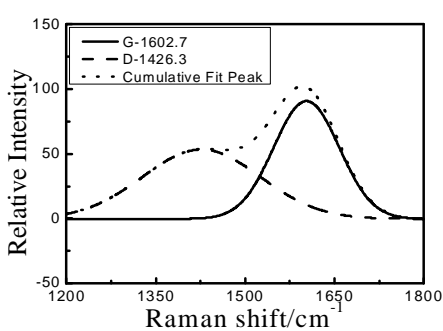

Fig. 5 DLC film Raman spectroscopy 
Tab. 4 Sample elements relative content

\begin{tabular}{|c|c|c|c|c|c|c|c|c|}
\hline Name & $\begin{array}{l}\text { Start } \\
\text { BE }\end{array}$ & $\begin{array}{c}\text { Peak } \\
\text { BE }\end{array}$ & $\begin{array}{l}\text { End } \\
\text { BE }\end{array}$ & $\begin{array}{l}\text { Height } \\
\text { Counts }\end{array}$ & $\begin{array}{c}\text { FWHM } \\
\text { eV }\end{array}$ & $\begin{array}{l}\text { Area (P) } \\
\text { CPS.eV }\end{array}$ & $\begin{array}{c}\text { Area } \\
(\mathrm{N})\end{array}$ & $\begin{array}{l}\text { At. } \\
\%\end{array}$ \\
\hline $\mathrm{Al}_{2 \mathrm{p}}$ & 77.7 & 71.67 & 68.2 & 537.11 & 0.18 & 1159.44 & 0.01 & 0.58 \\
\hline $\mathrm{C}_{1 \mathrm{~s}}$ & 292.1 & 284.23 & 279.6 & 161698.7 & 1.86 & 350852.4 & 2.23 & 98.22 \\
\hline $\mathrm{Ti}_{2 \mathrm{p}}$ & 469.1 & 464.79 & 449.1 & 1320.73 & 0.21 & 5391.79 & 0 & 0.2 \\
\hline $\mathrm{O}_{1 \mathrm{~s}}$ & 535.9 & 531.45 & 526.1 & 2731.22 & 1.13 & 9835.67 & 0.02 & 1 \\
\hline \multicolumn{9}{|c|}{ Tab. 5 Raman spectra of Peak } \\
\hline & \multicolumn{3}{|c|}{ Peak $/ \mathrm{cm}^{-1}$} & \multicolumn{2}{|c|}{ Half weigh $/ \mathrm{cm}^{-1}$} & \multirow{2}{*}{\multicolumn{2}{|c|}{$\begin{array}{l}\text { Strength ratio } \\
\qquad \mathrm{I}_{(\mathrm{D})} / \mathrm{I}_{(\mathrm{G})}\end{array}$}} & \\
\hline & & & G & $\mathrm{D}$ & G & & & \\
\hline & \multicolumn{2}{|c|}{1426.3} & 1602.7 & 232.88 & 129.79 & 1.056 & & \\
\hline
\end{tabular}

\section{Friction and wear test}

\section{Dry friction performance}

Figure 6 shows the friction coefficient curve of different spacing stripe composite modification surface under dry friction condition. It can be seen that all the composite modified surfaces have the effect of reducing friction. The effect of composite modification on the reduction of friction is not much different from the previous study [9]. The friction coefficient of 50um stripe composite modification surface is not reduced (the friction coefficient of non film surface is $0.11 \sim 0.14$ ), but increased. The reason is that the binding force between the deposited DLC film and the matrix is not strong and the general DLC film has a large internal stress. The wear debris is more easy produce when the texture size is smaller and the DLC film structure is more complex. So the friction coefficient increased. The friction coefficient of the $100 \mathrm{um}$ film is also increased (the friction coefficient of composite modification surface is $0.15 \sim 0.17$ and the textured surface is 0.14 0.15). The friction coefficient change of the 150um stripe textured surface before and after DLC film deposited is little. The friction coefficient of $1 \mathrm{~N}$ and $2 \mathrm{~N}$ is stable at 1.3 . The friction coefficient of 200um stripe textured composite modification surface is decreased slightly. The friction coefficient is $0.15 \sim 0.18$ and the friction coefficient of non film textured surface is $0.17 \sim 0.18$. It can be seen from Figure 6 that the friction coefficient is very stable and the reducing friction effect is very obvious under $2 \mathrm{~N}$. The friction coefficient of composite modification surface is less than 0.15 , which compared to 0.17 of the non film textured surface. The analysis shows that the deposition of DLC film is effective in enhancing the matrix hardness and reducing the friction coefficient. But it is difficult to play a obvious role when deposited on the small size texture surface because of thinner thickness and high internal stress. As to the large size texture surface, the reduction effect is not obvious yet due to the etching edge and not polished matrix.
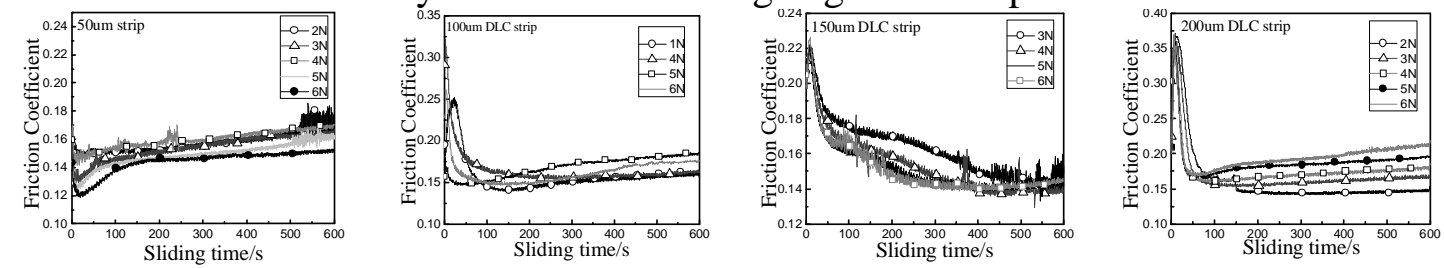

Fig. 6 Friction coefficient of different spacing stripe composite modification surface under dry friction condition

\section{Friction properties under oil bath lubrication}

Figure 6 shows the friction coefficient curve of different spacing stripe composite modification surface under oil bath lubrication. It can be seen from the graph that the friction coefficient changes were very smooth. The friction coefficient increased with the stripe size increased and the effect of load to friction coefficient was small. Previous studies have pointed out that the DLC film has no significant effect on the friction reduction of the stripe texture surface due to its own properties and the etching edge and not polished matrix. But the anti-wear property was significantly improved. It 
can be seen from figure 8 that all the DLC deposited surface still have good texture, there were no obvious wear scar appeared even at the condition of $6 \mathrm{~N}$ load. In contrast to this, the surface texture of uncoated surface has basically been removed under $3 \mathrm{~N}$ loading conditions in the previous study.
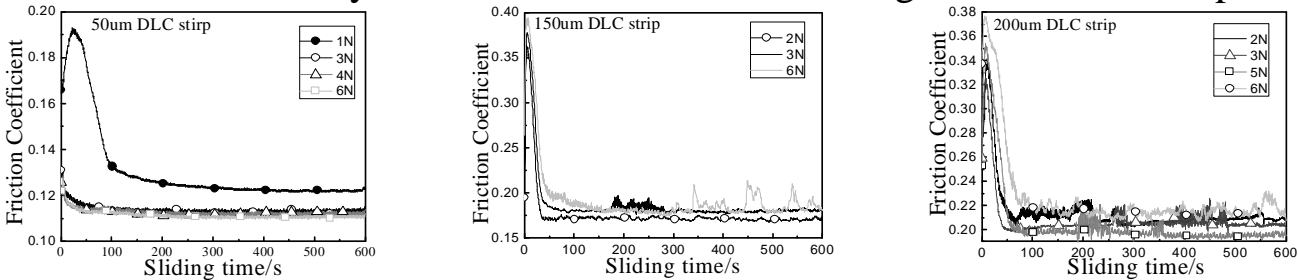

Fig. 7 Friction coefficient of different spacing stripe composite modification surface under oil bath lubrication
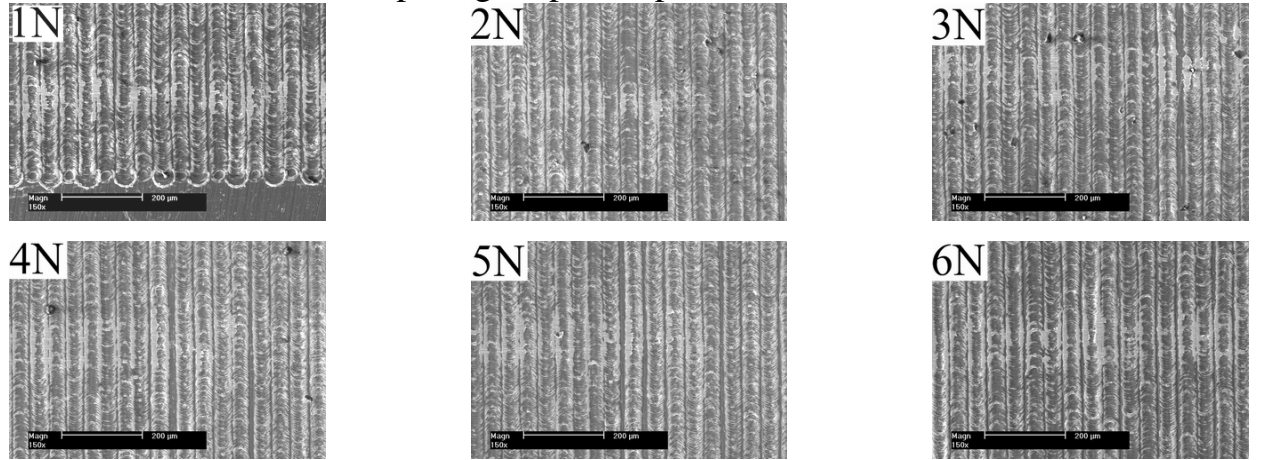

Fig. 8 Wear morphology of 50 micron diameter composite modified surface under different loads

\section{Conclusions}

(1) A series of texture clear, shape rules equal width stripe were prepared on the surface of titanium alloy by using laser processing technology. The film deposited on the textured surface was standard DLC film.

(2) The composite modification surface had an anti-friction effect under dry friction condition. The friction coefficient of the $150 \mathrm{um}$ stripe composite modification surface was lowest under $1 \mathrm{~N} \sim 2 \mathrm{~N}$ load, which was 0.13 . The friction coefficient of the $250 \mathrm{um}$ stripe composite modification surface was lowest under $3 \mathrm{~N} \sim 6 \mathrm{~N}$ load, which was $0.15 \sim 0.18$.

(3) The composite modification surface had good anti-wear property in the oil lubricated condition. There were no obvious wear scar appeared even at the condition of $6 \mathrm{~N}$ load.

\section{Acknowledgement}

This research was financially supported by the Scientific Research Foundation of Yunnan Education Department(51400630)

\section{References}

[1] Liang Chunyong. Micro-patterned Treatment of Ti alloy Surface and Its Biological Activation Machanism[D]. Doctoral Dissertation of Tianjin University, 2008.

[2] H. C . Man, Z. D. Cui, T. M. Yue. Cavitation erosion behavior of laser gas nitrided Ti and Ti6A14VAlloy[J]. Materials Science and Engineering, 2003, A355: 167-173 .

[3] Chen Xiaolin. Surface Texturing and Plasma Nitriding Treatment of Titanium Alloy and Study of Its Bio-tribological Properties[D], Master degree thesis of Nanjing University of Science and Technology, 2008.

[4] Etsion I, Sher E. Improving fuel efficiency with laser surface textured piston rings [J]. Tribology Internationa1, 2009, 42: 542-547

[5] Costa H L, Hutchings I M. Hydrodynamic lubrication of textured steel surface under reciprocating sliding conditions [J]. Trihology International, 2007, 40: 1227-1238.

[6] Lin Songsheng, Dai Mingjiang, Li Hongwu, et al. Study on Friction and Wear Performance of 
Mental Doped Diamond-like Carbon Film on Titanium Alloy Surface[J]. Tribology, 2007, 27(4): 382-385.

[7] Huang Weijiu, Li Zhaofeng, Wang Guo, et al. Study on the Tribological Properties and Corrosion Resistance of Diamond-Like Multilayer Films on Ti6Al4V Alloy Surface[J]. Rare materials and engneering, 2010, (7): 1-6.

[8] Liu Jianli, Wang Zhi, Zhang Yujuan, et al. Tribological Characterization and Corrosion Behavior of DLC Films on Ti6A14V Alloy[J]. Rare materials and engneering, 2011, 40(2): 255-258.

[9] Zhang Yonghai, Chen Wengang, Shi Bing. Tribological properties analysis of laser surface textured titanium alloy[J]. Material protection, 2013, 46(supplementary issue): 48-51. 